\title{
Fast-freezing with liquid nitrogen preserves bulk dissolved organic matter concentrations, but not its composition
}

\author{
Lisa Thieme $^{1,2}$, Daniel Graeber ${ }^{3}$, Martin Kaupenjohann ${ }^{1}$, and Jan Siemens ${ }^{2}$ \\ ${ }^{1}$ Chair of Soil Science, Department of Ecology, Technical University of Berlin, Berlin, Germany \\ ${ }^{2}$ Chair of Soil Resources, Institute of Soil Science and Soil Conservation, iFZ Research Centre for Biosystems, Land Use and \\ Nutrition, Justus-Liebig University Giessen, Giessen, Germany \\ ${ }^{3}$ Department of Bioscience, Catchment Science and Environmental Management, Aarhus University, Silkeborg, Denmark \\ Correspondence to: Lisa Thieme (1.thieme@ campus.tu-berlin.de)
}

Received: 15 March 2016 - Published in Biogeosciences Discuss.: 22 March 2016

Revised: 19 July 2016 - Accepted: 20 July 2016 - Published: 22 August 2016

\begin{abstract}
Freezing can affect concentrations and spectroscopic properties of dissolved organic matter (DOM) in water samples. Nevertheless, water samples are regularly frozen for sample preservation. In this study we tested the effect of different freezing methods (standard freezing at $-18^{\circ} \mathrm{C}$ and fast-freezing with liquid nitrogen) on DOM concentrations measured as organic carbon (DOC) concentrations and on spectroscopic properties of DOM from different terrestrial ecosystems (forest and grassland). Fresh and differently frozen throughfall, stemflow, litter leachate and soil solution samples were analyzed for DOC concentrations, UV-vis absorption and fluorescence excitation-emission matrices combined with parallel factor analysis (PARAFAC). Fast-freezing with liquid nitrogen prevented a significant decrease of DOC concentrations observed after freezing at $-18^{\circ} \mathrm{C}$. Nonetheless, the share of PARAFAC components 1 $\left(\mathrm{EX}_{\max }<250 \mathrm{~nm}(340 \mathrm{~nm}), \mathrm{EX}_{\max }: 480 \mathrm{~nm}\right)$ and $2\left(\mathrm{EX}_{\max }\right.$ : $335 \mathrm{~nm}, \mathrm{EX}_{\max }: 408 \mathrm{~nm}$ ) to total fluorescence and the humification index (HIX) decreased after both freezing treatments, while the shares of component $3\left(\mathrm{EX}_{\max }:<250 \mathrm{~nm}(305 \mathrm{~nm})\right.$, $\mathrm{EX}_{\max }: 438 \mathrm{~nm}$ ) as well as $\mathrm{SUVA}_{254}$ increased. The contribution of PARAFAC component $4\left(\mathrm{EX}_{\max }: 280 \mathrm{~nm}, \mathrm{EX}_{\max }\right.$ : $328 \mathrm{~nm}$ ) to total fluorescence was not affected by freezing. We recommend fast-freezing with liquid nitrogen for preservation of bulk DOC concentrations of samples from terrestrial sources, whereas immediate measuring is preferable to preserve spectroscopic properties of DOM.
\end{abstract}

\section{Introduction}

In addition to dissolved organic carbon (DOC) concentrations, properties of dissolved organic matter (DOM) are crucial for its role in biogeochemical cycles of carbon and nutrients as well as for its effect on pollutant dynamics (Bolan et al., 2011). Spectroscopic methods like UV-vis absorption and fluorescence spectroscopy used as single excitationemission scans, synchronous scans and excitation-emission matrices (EEMs) in combination with different indices and/or parallel factor analysis (PARAFAC) are increasingly applied to characterize chromophoric dissolved organic matter (cDOM) in various environments (e.g., Murphy et al., 2008; Yamashita et al., 2010; Stedmon and Markager, 2005; Graeber et al., 2012; Otero et al., 2007, Traversa et al., 2014; Kalbitz et al., 1999).

The applicability of optical methods for characterizing DOM and the comparability of results in multidisciplinary studies relies on the preservation of samples prior to their analysis. DOM properties depend on many physicochemical and biological boundary conditions, so that artifacts caused by sample storage or sample pre-treatment may be produced easily. For these reasons it is recommended to directly filter samples after collection and store them in the cold and dark prior to measurement as soon as possible (Santos et al., 2010; Spencer and Coble, 2014). However, immediate measurement is often not possible for practical reasons such as a large number of samples or remote or separated sampling sites, so that freezing of filtered DOM samples is often the selected storage method (Murphy et al., 2008; Yamashita et al., 2010; 
Graeber et al., 2012). Freezing can affect the physicochemical composition of samples (Edward and Cresser, 1992), so that improved conservation techniques, which avoid or minimize potential artifacts of freezing, are required. During the freezing process, DOM is preferentially excluded from the ice phase and enriched in the remaining liquid phase (Belzile et al., 2002; Xue et al., 2015). The increasing solute concentrations and changing physical conditions in the remaining liquid phase during the freezing process could promote conformational and configurational changes of DOM molecules as well as particle and complex formation depending on DOM composition and sample type (Zaritzky, 2006; Edward and Cresser, 1992). One potential technique for minimizing these effects could be fast freezing with liquid $\mathrm{N}_{2}$, by radically reducing the freezing time.

Whereas studies on sample preservation of marine waters (Del Castillo and Coble, 2000; Yamashita et al., 2010a; Conmy et al., 2009) showed only small freezing effects on DOM fluorescence characteristics, research with a variety of freshwater samples produced inconsistent results. Fellman et al. (2008) measured DOC concentrations and UV absorption in fresh and frozen and/or thawed Alaska stream water samples and reported a significant decrease of DOC concentration and specific ultraviolet absorption at $254 \mathrm{~nm}\left(\mathrm{SUVA}_{254}\right)$. They recommended freezing as an acceptable storage method for freshwater samples with low DOC concentration and/or low $\mathrm{SUVA}_{254}$ values. In contrast, Yamashita et al. (2010) observed only minor changes in absorption-based indices after freezing and thawing of Venezuela river water but significant alterations (decrease and increase) for PARAFAC component intensities. A freeze-thaw experiment with water samples from a large number of UK locations conducted by Spencer et al. (2007) showed large and variable changes (decreasing and increasing) in DOM fluorescence intensity and absorbance after freezing and thawing. Likewise Peakock et al. (2015) found strong and inconsistent effects of freezing and thawing on absorbance properties of cDOM in water from bog pools, fen ditches and lakes. In a study of sample preservation on rainwater cDOM fluorescence, Santos et al. (2010) found a decrease of protein-like fluorescence intensity due to freezing.

While many studies investigated the influence of different soil sample pre-treatments on DOC concentrations and DOM composition (e.g., Christ and David, 1994; Sun et al., 2015) only few studies focused on the influence on these properties when using different preservation methods for the extracted soil solutions. Otero et al. (2007) conducted freeze-thaw experiments on salt marsh pore water and found no changes in characteristics of synchronous fluorescence scans.

The impact of sample preservation like freezing seems highly variable depending on sample and DOM characteristics. While most studies focused on samples from marine or freshwater ecosystems, there is a lack of information on sample pre-treatment effects on cDOM properties of water samples from terrestrial ecosystems, especially soil solution. Due to different sources of DOM in land and water environments (Bolan et al., 2011) and therefore different chemical characteristics, it is unlikely that insights regarding the alterations of samples during storage can be transferred from one sample type to another. To help close this gap, we investigate in this study the influence of freezing and thawing on DOC concentration, spectral absorption and fluorescence properties for a wide range of water samples (throughfall, litter leachate and soil solution) from different terrestrial ecosystems (grasslands and forests). We tested in how far fast-freezing with liquid nitrogen might prevent concentration and partitioning effects and minimize structural changes of DOM. We hypothesized (i) that sample type affects freeze-thaw effects on DOC concentrations and DOM properties, because of different physical and chemical DOM characteristics and therefore different response to changing conditions during freezing and (ii) that fast-freezing with liquid nitrogen reduces these freeze-thaw effects, because it minimizes the freezing time and thus prevents partitioning effects and their physical consequences.

\section{Material and methods}

\subsection{Study sites}

The study was conducted on experimental plots in the Schorfheide Chorin Exploratory of the German "Biodiversity Exploratories", which were established as platform for largescale and long-term functional biodiversity research (Fischer et al., 2010). The experimental plots are located in a young glacial landscape in NE Germany with an annual mean temperature of 8 to $8.5^{\circ} \mathrm{C}$ and an annual mean precipitation of 500 to $600 \mathrm{~mm}$. The forest plots are dominated either by pine (Pinus sylvestris L.) or beech (Fagus sylvatica L.) on Cambisols (IUSS working group WRB, 2014). The grassland plots are meadows, pastures and mown pastures on Histosols, Gleysols and Cambisols.

\subsection{Sampling and sample preparation}

For the experiments, we collected solution samples from five forest and three grassland plots on 17 and 18 June 2014 within a bi-weekly 2-day sampling routine of above and below-ground water samples in the DFG priority program "Biodiversity Exploratories". Together we collected 27 samples for the freezing experiment including six throughfall (TF), five stemflow (SF), five forest litter leachate (LL) as well as six top- and five subsoil solution samples. Volumeweighted composite samples for the experiment were produced from replicated samplers of the same type (e.g., throughfall collectors, shallow suction cups) of one plot in "aged" $500 \mathrm{~mL}$ PE bottles. The bottles were bi-weekly used in the field for the same samples, after washing in the dishwasher and with deionized water. TF was sampled with funnel-type collectors (diameter $0.12 \mathrm{~m}$, polyethylene) $0.3 \mathrm{~m}$ 
above soil surface. We pooled five replicates at grassland and 20 replicates arranged in two lines of 10 samplers in a cross-shaped form at forest sites. To minimize alterations of the sample and contamination such as evaporation, photo chemical reactions and algae growth, the sampling bottles were wrapped with aluminium foil and closed with a $1.6 \mathrm{~mm}$ polyester mesh and a table-tennis ball. SF was sampled with sliced polyurethane hoses (diameter: $0.04 \mathrm{~m}$ ) as a collar sealed with a polyurethane-based glue to the bark of three trees per site at approximately $1.5 \mathrm{~m}$ height and connected with a polypropylene (PP) or polyethylene (PE) barrel via a PE tube. LL was collected with three zero-tension lysimeters per site $\left(280 \mathrm{~cm}^{2}\right.$ sampling area) consisting of polyvinyl chloride plates covered with a PE net (mesh width $0.5 \mathrm{~mm}$ ) connected with PE hoses to $2 \mathrm{~L}$ PE bottles stored in a box below ground. We sampled soil solution with nylon membrane $(0.45 \mu \mathrm{m})$ suction cups (ecoTech, Germany). Three samplers were installed beneath the A horizon (Top) at approximately $10 \mathrm{~cm}$ depth. Another three were installed in the B horizon (Sub) in approximately $50 \mathrm{~cm}$ depth in the forest plots and 60 or $70 \mathrm{~cm}$ depth in the grassland sites. Suction cups were connected to $2 \mathrm{~L} \mathrm{PE}$ bottles in an insulated aluminium box placed into a soil pit. Soil water was extracted by applying a vacuum of $50 \mathrm{kPa}$ to the PE bottles with an electric pump after each sampling.

After mixing, the samples were transported on ice to the laboratory and stored overnight at $5{ }^{\circ} \mathrm{C}$. We measured $\mathrm{pH}$ (Knick, Germany) and electrical conductivity (WTW, Germany) in all samples prior to filtration through $\sim 0.7 \mu \mathrm{m}$ glass microfiber filters (Whatman GF/F). The filters were washed with $100 \mathrm{~mL}$ deionized water and $10 \mathrm{~mL}$ of sample before sample filtration. The filtered sample was split in three aliquots for different preservation treatments: (i) no preservation (fresh) for which samples were stored at $5{ }^{\circ} \mathrm{C}$ in the dark and DOC concentrations were measured $24 \mathrm{~h}$ after sampling while fluorescence as well as absorbance were measured within $48 \mathrm{~h}$; (ii) preservation by freezing for which the samples were stored at $-18^{\circ} \mathrm{C}$ for 4 weeks, and (iii) fastfreezing with liquid nitrogen $\left(\mathrm{N}_{2}\right)$, for which $12 \mathrm{~mL}$ sample aliquots were filled in pre-rinsed $15 \mathrm{~mL}$ ( $5 \mathrm{~mL}$ sample) PP falcon tubes, dipped in liquid nitrogen for $30 \mathrm{~s}$ and then stored at $-18^{\circ} \mathrm{C}$ for 42 days. Fresh samples and samples frozen at $-18^{\circ} \mathrm{C}$ were stored in $20 \mathrm{~mL}$ PE scintillation vials (NeoLab) that were pre-rinsed with $5 \mathrm{~mL}$ sample before filling. Fluorescence, absorbance and DOC concentration from all frozen samples were measured after defrosting over night at $5{ }^{\circ} \mathrm{C}$ in the dark. For all preparation steps and treatments control samples of ultrapure water (EVOQUA, Germany) were analyzed, showing no release of DOM (DOC concentration and DOM fluorescence) from laboratory equipment.

\subsection{Laboratory analysis}

We measured the concentration of DOC as non-purgeable organic carbon on a Shimadzu TOC-5050A (Duisburg, Ger- many) with a limit of quantification of $2 \mathrm{mg} \mathrm{C} \mathrm{L}^{-1}$. Absorption spectra of DOM were scanned at wavelength from 400 to $600 \mathrm{~nm}$ using a Lambda $20 \mathrm{UV}$-vis spectrometer (Perkin Elmer, USA) and a $1 \mathrm{~cm}$ quartz cuvette. Absorbance measurements were baseline corrected using ultrapure water. All fluorescence EEMs were measured on a Hitachi F-4500 fluorescence spectrometer (Hitachi, Japan) directly after absorption measurement in the same cuvette. We measured excitation from 240 to $450 \mathrm{~nm}$ ( $5 \mathrm{~nm}$ steps) and emission from 300 to $600 \mathrm{~nm}(2 \mathrm{~nm}$ steps $)$ with a slit width of $5 \mathrm{~nm}$ and scan speed $12000 \mathrm{~nm} \mathrm{~min}{ }^{-1}$. We corrected our EEMs according to the protocol from Murphy (2010) with the fdomcorrect function in the drEEM toolbox (version 2.0) of Murphy et al. (2013) using Matlab (Version Matlab2011b, The MathWorks Inc.). We used the correction curves supplied by the manufacturer for the excitation and emission correction factors. We measured ultrapure water fluorescence spectra for blank correction and to convert EEMs to Raman units by normalizing them to the area under the Raman peak at $350 \mathrm{~nm}$ excitation wavelength (Lawaetz and Stedmon, 2009). In order to apply the inner-filter correction of Lakowicz (2006) integrated in the drEEM toolbox, all aliquots were diluted with ultrapure water to achieve an absorption of $<0.3$ at $254 \mathrm{~nm}$ (Ohno, 2002). For this reason, not all treatments of one sample were diluted with the same dilution factor. To test the possible influence of different dilutions on the $\mathrm{pH}$ related changes in fluorescence (Patel-Sorrentino et al., 2002; Baker et al., 2007), dilution series with samples $(n=14)$ from the same plots and same sample types but with different sampling dates were measured for $\mathrm{pH}$, absorption and fluorescence according to the protocol described above. We compared the differences of 31 dilutions and calculated the mean absolute deviation (MAD). These were compared to the MAD of measurement precision, determined by analyzing 11 samples in three replications. For the PARAFAC components $\% \mathrm{C} 1, \% \mathrm{C} 2$ and $\% \mathrm{C} 3$ and $\mathrm{SUVA}_{254}$ the MAD caused by dilution were less or equal than the precision MAD, so that there was no influence of dilution on the three humic-like components and the specific UV absorbance at $254 \mathrm{~nm}$. For $\% \mathrm{C} 4$ and HIX the effect of dilution could exceed the precision of fluorescence measurements. For detailed information see supporting information.

\subsection{Spectroscopic indices and PARAFAC modeling}

Based on the absorbance spectra, we calculated specific ultraviolet absorbance $\left(\mathrm{SUVA}_{254}\right)$ as the absorbance at $254 \mathrm{~nm}$ divided by the DOC concentration. The $\mathrm{SUVA}_{254}$ is reported in $\mathrm{L} \mathrm{mg}^{-1} \mathrm{~m}^{-1}$, and is associated with bulk aromaticity (Weishaar et al., 2003). Moreover, we calculated the humification index (HIX) from fluorescence EEMs (Ohno, 2002). The HIX ranges from 0 to 1 and allows characterizing samples based on their degree of DOM humification.

In addition to the calculation of indices, we used parallel factor analysis (PARAFAC) to mathematically decom- 
pose the trilinear data of the EEMs into fluorescence components of DOM (Stedmon et al., 2003). Further pre-processing steps of EEMs (smoothing of Rayleigh and Raman scatter and sample normalization), as well as the PARAFAC analysis, were conducted with the drEEM toolbox (version 2.0, Murphy et al., 2013). We chose a four component PARAFAC model (components referred as $\mathrm{C} 1$ to $\mathrm{C} 4$ ), visually checked the randomness of residuals and the component spectral loadings, split-half validated the model and generated the best fit by random initialization. For comparison in statistical analysis we used the relative percentage distribution of the four PARAFAC components ( $\%$ of the sum of total peak fluorescence of all PARAFAC components), so that percentage values for the components will be given as $\% \mathrm{C} 1$ to $\% \mathrm{C} 4$.

\subsection{Statistical analysis}

The DOM composition variables used for statistical analysis were the PARAFAC components $\% \mathrm{C} 1$ to $\% \mathrm{C} 4$, the spectroscopic indices HIX and $\mathrm{SUVA}_{254}$, as well as the DOC concentration. For all statistical analysis the variables were scaled and centered. We conducted a pair-wise (samples as strata) permutational multivariate analysis of variance (PERMANOVA) with DOC concentrations of the fresh samples as factor based on Euclidean distances in R (Oksanen et al., 2015; $\mathrm{R}$ core team, 2015). The adonis function was used to assess the influence of sample preparation (fresh, frozen, fast-freezing) and of the initial DOC concentration on DOM variables. To investigate preservation effects on single variables we conducted linear mixed-effect models (sometimes called multi-level models, lme function, Linear and Nonlinear Mixed Effects Models package for R, Pinheiro et al., 2015) with samples as random intercept on each of the DOM composition variables. These were used instead of simple linear models or ANOVAs, since we could not expect the same intercept for all samples due to different sample concentrations. To test the influence of the initial DOC concentration on single preservation treatments we performed Spearman Rank Order Correlation. To assess the influence of sample type (TF, SF, LL, Top or Sub) on the relative change of DOM composition due to fast-freezing with liquid nitrogen or freezing at $-18^{\circ} \mathrm{C}$ in relation to the measurement of fresh, cooled samples, we used an ANOVA with the sample type as fixed factor (aov function in R). To remove sample concentration-related effects and to calculate relative changes, the differences between the two preservations (either fast-freezing or freezing at $-18^{\circ} \mathrm{C}$ ) relative to the measurements of fresh samples were calculated for each sample before the ANOVA. This was only done for variables, for which we found strong, significant effects with the linear mixed-effect models.

\section{Results}

\subsection{DOM concentrations}

The samples covered a wide range of DOC concentrations (Fig. 1a, b). Fresh TF samples showed the lowest concentrations ranging from 5 to $17 \mathrm{mg} \mathrm{C} \mathrm{L}^{-1}$, SF samples had the highest DOC concentrations ranging from 12 to $138 \mathrm{mg} \mathrm{C} \mathrm{L}^{-1}$ (Fig. 1b). High concentrations up to $75 \mathrm{mg} \mathrm{C}$ $\mathrm{L}^{-1}$ were also found for LL samples, but average values were smaller than for SF (Fig. 1b). In the mineral soil, concentrations decreased from 13 to $124 \mathrm{mg} \mathrm{C} \mathrm{L}^{-1}$ in topsoil samples to 9 to $47 \mathrm{mg} \mathrm{C} \mathrm{L}^{-1}$ in subsoil samples.

We found a significant treatment effect (linear mixedeffect models (lme), $p<0.05$ ) on DOC concentration when comparing the fresh and frozen samples (Fig. 1c). In 24 of 27 samples DOC concentrations decreased after freezing at $-18^{\circ} \mathrm{C}$ and subsequent thawing, with an average change of $-1.6 \mathrm{mg} \mathrm{C} \mathrm{L}^{-1}$ or $-6 \%$ respectively. The maximum decrease that was found equalled $-6 \mathrm{mg} \mathrm{C} \mathrm{L}^{-1}$ and $-25 \%$, respectively. In contrast to freezing at $-18{ }^{\circ} \mathrm{C}$, fast-freezing with liquid nitrogen did not result in significant changes (lme, $p>0.05$ ) of DOC concentrations (Fig. 1c). This different behavior between normal freezing and fast-freezing was also found for the influence of the initial DOC concentration on changes of DOM properties. Only the $-18^{\circ} \mathrm{C}$ treatment showed a significant correlation (Spearmans rank $r=$ $-0.447, p=0.0194)$, indicating a larger decrease of DOC concentrations due to freezing for samples with higher initial DOC concentrations.

\subsection{PARAFAC fluorescence components}

The analysis of fluorescence spectra using PARAFAC resulted in four components that were characterized according to the review of Fellman et al. (2010) (Table 1). C1 exhibited its main excitation maximum at $<250 \mathrm{~nm}$, a secondary maximum at $340 \mathrm{~nm}$ and an emission maximum at $480 \mathrm{~nm}$ and was described as UVA humic-like fluorophore with a terrestrial source and a high molecular weight (Murphy et al., 2006; Stedmon et al., 2003; Shutova et al., 2014; Fellman et al., 2010). C2 had a maximum excitation at $335 \mathrm{~nm}$ and an emission maximum at $408 \mathrm{~nm}$ and was named also UVA humic-like, but associated with low molecular weight (Murphy et al., 2006; Fellman et al., 2010; Stedmon et al., 2003). $\mathrm{C} 3$ was defined by an excitation maximum at $<250 \mathrm{~nm}$, a secondary maximum at $305 \mathrm{~nm}$ and an emission maximum at $438 \mathrm{~nm}$. This component dominated fulvic acid fractions of humic substances (Santín et al., 2009; He et al., 2006). Finally, $\mathrm{C} 4$ was characterized by its excitation maximum at $280 \mathrm{~nm}$ and an emission maximum at $328 \mathrm{~nm}$ and was classified as tryptophan-like, as its fluorescence resembles free tryptophan. Therefore, this component was associated with free or bound proteins (Fellman et al., 2010). 


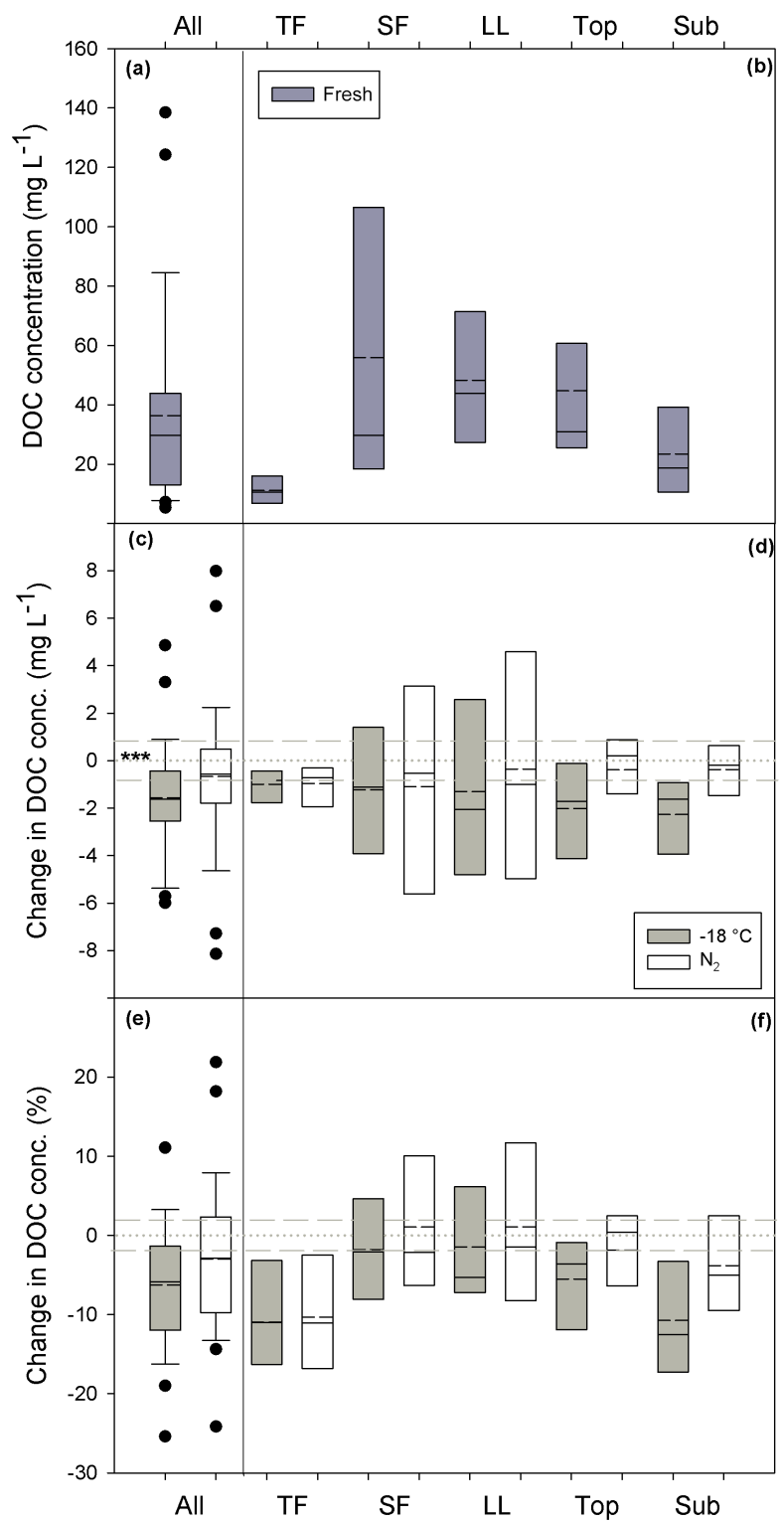

Figure 1. Absolute DOC concentrations (measured in fresh samples) and changes in DOC concentrations after freezing $\left(-18^{\circ} \mathrm{C}\right)$ and fast-freezing with liquid nitrogen; (a, c, e) all samples $(n=27)$; (b, d, f) ordered by sample type (throughfall (TF) $n=6$, stemflow (SF) $n=5$, litter leachate (LL) $n=5$, top soil solution (Top) $n=6$, sub-soil solution (Sub) $n=5$ ); gray dashed line: analytical reproducibility; ${ }^{* * *}$ significant changes (linear mixed models (lme), $p<0.05$ ); boxplots: solid line: median, dashed line: mean.

We found different distributions of PARAFAC components for different sample types (Fig. 2). The contribution of $\% \mathrm{C} 1$ to the total fluorescence increased from $\mathrm{TF}$ over SF to LL and then decreased again from LL to Sub (Fig. 2), while $\% \mathrm{C} 2$ showed just the opposite trend. In contrast, \% 3 tended to increase from $\mathrm{TF}$ to Sub, whereas \% 4 showed a decreasing trend (Fig. 2).
Table 1. Characteristics of PARAFAC components based on Fellman et al. (2010).

\begin{tabular}{lrrl}
\hline Component & $\begin{array}{r}\text { Maximum exitation } \\
\text { wavelength(EX }\end{array}$ \\
& $(\mathrm{nm})$ & $\begin{array}{r}\text { Maximum emission } \\
\text { wavelength }\left(\mathrm{EM}_{\max }\right) \\
(\mathrm{nm})\end{array}$ & \\
\hline $\mathrm{C} 1$ & $<250(340)$ & 480 & humic-like, terrestrial \\
$\mathrm{C} 2$ & 335 & 408 & humic-like \\
$\mathrm{C} 3$ & $<250(305)$ & 438 & fulvic-acid-type \\
$\mathrm{C} 4$ & 280 & 328 & tryptophan-like \\
\hline
\end{tabular}
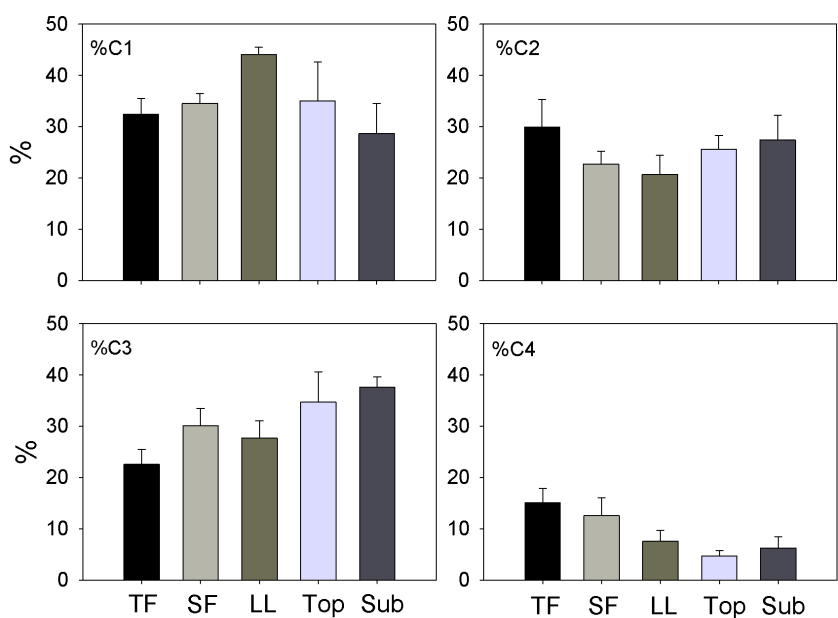

Figure 2. Mean distribution of PARAFAC components \%C1-\%C4 for different sample types.

The conducted PERMANOVA was highly significant $(p<0.001)$, indicating that the preservation significantly affects the DOM composition. The interaction between treatment and initial DOC concentration of the fresh treatment explains a reasonable part of the variance $\left(R^{2}=0.14\right)$ and is highly significant $(p<0.001)$. Therefore the original DOC concentration of the fresh sample well explains the variable strength of the treatment effect.

Similar changes in component distribution were found as a consequence of freezing at $-18^{\circ} \mathrm{C}$ and fast-freezing with liquid nitrogen (Fig. 3). We observed a significant (lme, $p<0.05$ ) decrease in all samples for the relative fraction of the humic-like components $\% \mathrm{C} 1$ and $\% \mathrm{C} 2$ after freezing at $-18^{\circ} \mathrm{C}$ and fast-freezing compared to the fresh control samples (Fig. 3a, b). The contribution of $\% \mathrm{C} 1$ to the total fluorescence decreased on average by $-3 \%$ with maximum changes of $-5 \%$ for freezing at $-18{ }^{\circ} \mathrm{C}$ and $-6 \%$ for fast-freezing with liquid nitrogen. The average decrease of $\% \mathrm{C} 2$ was $-3 \%$ and the maximum $-8 \%$ for both treatments.

In contrast to $\% \mathrm{C} 1$ and $\% \mathrm{C} 2$, the share of $\% \mathrm{C} 3$ to the total fluorescence intensity increased upon freezing (Fig. 3e, f). All samples frozen at $-18{ }^{\circ} \mathrm{C}$ showed an increase in the relative intensity of the $\% \mathrm{C} 3$ signal, with an average increase of $+6 \%$ for both treatments. The maximum increase was $10 \%$ (freezing at $-18^{\circ} \mathrm{C}$ ) and $12 \%$ (freezing with liquid $\mathrm{N}_{2}$ ). 


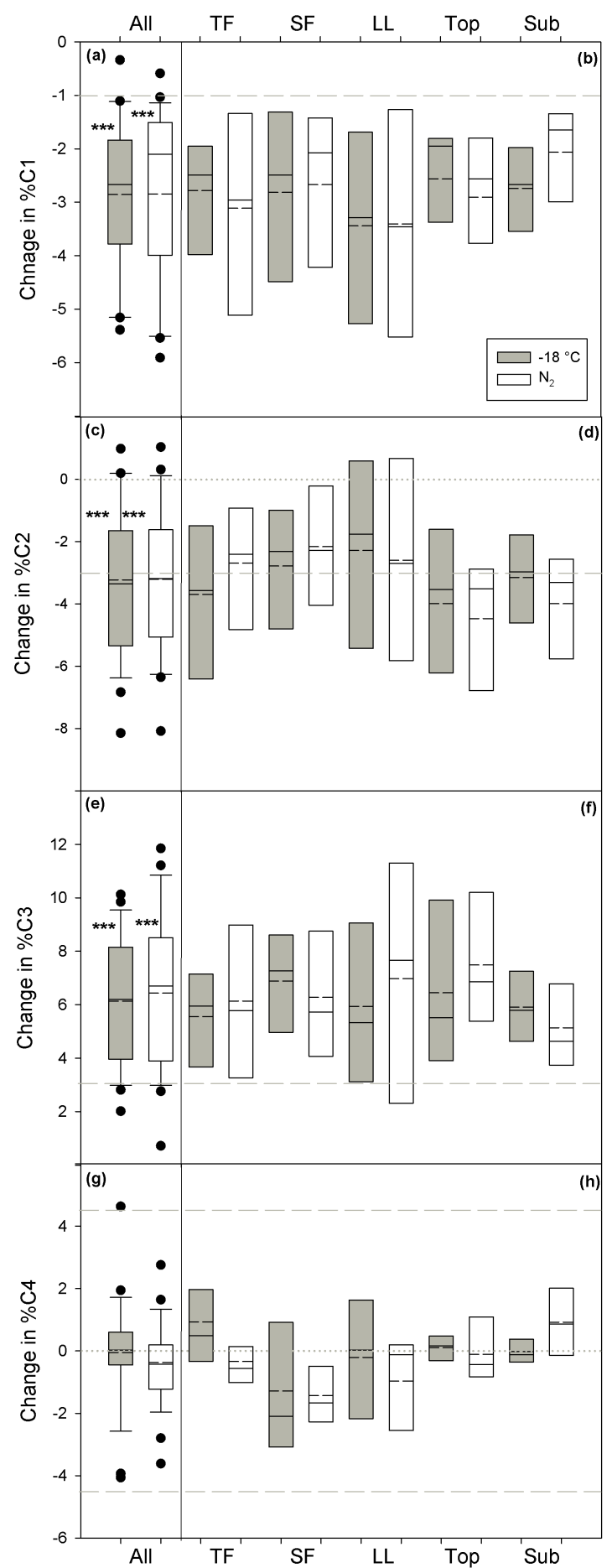

Figure 3. Changes of relative distribution of PARAFAC components after freezing $\left(-18^{\circ} \mathrm{C}\right)$ and fast-freezing with liquid nitrogen; (a, c, e, g) all samples $(n=27)$; $(\mathbf{b}, \mathbf{d}, \mathbf{f}, \mathbf{h})$ ordered by sample type (throughfall (TF) $n=6$, stemflow (SF) $n=5$, litter leachate (LL) $n=5$, top soil solution (Top) $n=6$, sub-soil solution (Sub) $n=5$ ); gray dashed line: analytical reproducibility; ${ }^{* * *}$ significant changes (linear mixed models (lme), $p<0.05$ ) ; boxplots: solid line: median, dashed line: mean.
No significant effects of sample preservation (lme, $p>0.05$ ) were found for \%C4, the protein-like component (Fig. 3g, h).

\subsection{Aromaticity and humification index}

We found SUVA 254 -values ranging from $1.1 \mathrm{~L} \mathrm{mg}^{-1} \mathrm{~m}^{-1}$ up to $4.5 \mathrm{~L} \mathrm{mg}^{-1} \mathrm{~m}^{-1}$ for fresh samples (Fig. $4 \mathrm{a}, \mathrm{b}$ ). Samples frozen at $-18^{\circ} \mathrm{C}$ and fast-frozen samples showed a significant increase (lme, $p<0.05$ ) of their $\mathrm{SUVA}_{254}$ (Fig. 4c). The average change was $+0.4 \mathrm{~L} \mathrm{mg}^{-1} \mathrm{~m}^{-1}$ equivalent to $+20 \%$ for samples frozen at $-18^{\circ} \mathrm{C}$ and $+0.5 \mathrm{~L} \mathrm{mg}^{-1} \mathrm{~m}^{-1}$ equivalent to $+24 \%$ for samples that were fast-frozen with liquid nitrogen.

The humification index of the freshly measured samples ranged from 0.806 to 0.931 in TF and SF samples and from 0.849 to 0.975 for Sub, Top and LL samples (Fig. 5a, b). We found a significant decrease (lme, $p<0.05$ ) of the HIX when comparing the freshly measured samples with the frozen and the fast-frozen samples (Fig. 5c). The average change was -0.016 or $-2 \%$ for samples frozen at $-18^{\circ} \mathrm{C}$ and -0.020 or $-2 \%$ for samples fast-frozen with liquid nitrogen. The maximum decrease was -0.128 or $-15 \%$ for $-18{ }^{\circ} \mathrm{C}$ samples and -0.076 or $-8 \%$ for liquid nitrogen samples (Fig. 5 c, d, e, f).

\section{Discussion}

We found that freezing at $-18^{\circ} \mathrm{C}$ significantly reduced DOC concentrations across all sample types and that the effect is higher with higher initial DOC concentrations. This is in line with results of Fellman et al. (2008) investigating the effect of freezing and thawing on Alaskan stream water samples. This loss of DOC concentration might be due to aggregation and irreversible particle formation (Giesy and Briese, 1978) induced by partitioning and concentration effects during the freezing process (Belzile et al., 2002; Xue et al., 2015). Indeed, our results indicated that fast-freezing with liquid nitrogen can prevent significant reductions of bulk DOC for samples with a large range of DOM concentrations. In contrast to effects on DOC concentrations, we found similar significant effects of fast-freezing as well as freezing at $-18^{\circ} \mathrm{C}$ on the chromophoric humic fraction of DOM (PARAFAC components, HIX and $\mathrm{SUVA}_{254}$ ). The increase of aromaticity as indicated by higher $\mathrm{SUVA}_{254}$ values indicates a stronger removal of non-aromatic DOM during freezing and thawing. On the other hand, the decrease in the HIX suggests a preferential removal of humified cDOM. One potential explanation for the fact that fast-freezing in liquid nitrogen resulted in significant changes of DOM fluorescence properties, but only small changes of bulk DOC concentrations, is that cDOM reacted stronger to freezing and thawing than the remaining DOM so that spectroscopic properties were affected, but bulk DOC concentrations were not. Fast freezing may have failed to prevent changes of cDOM composition because (i) 


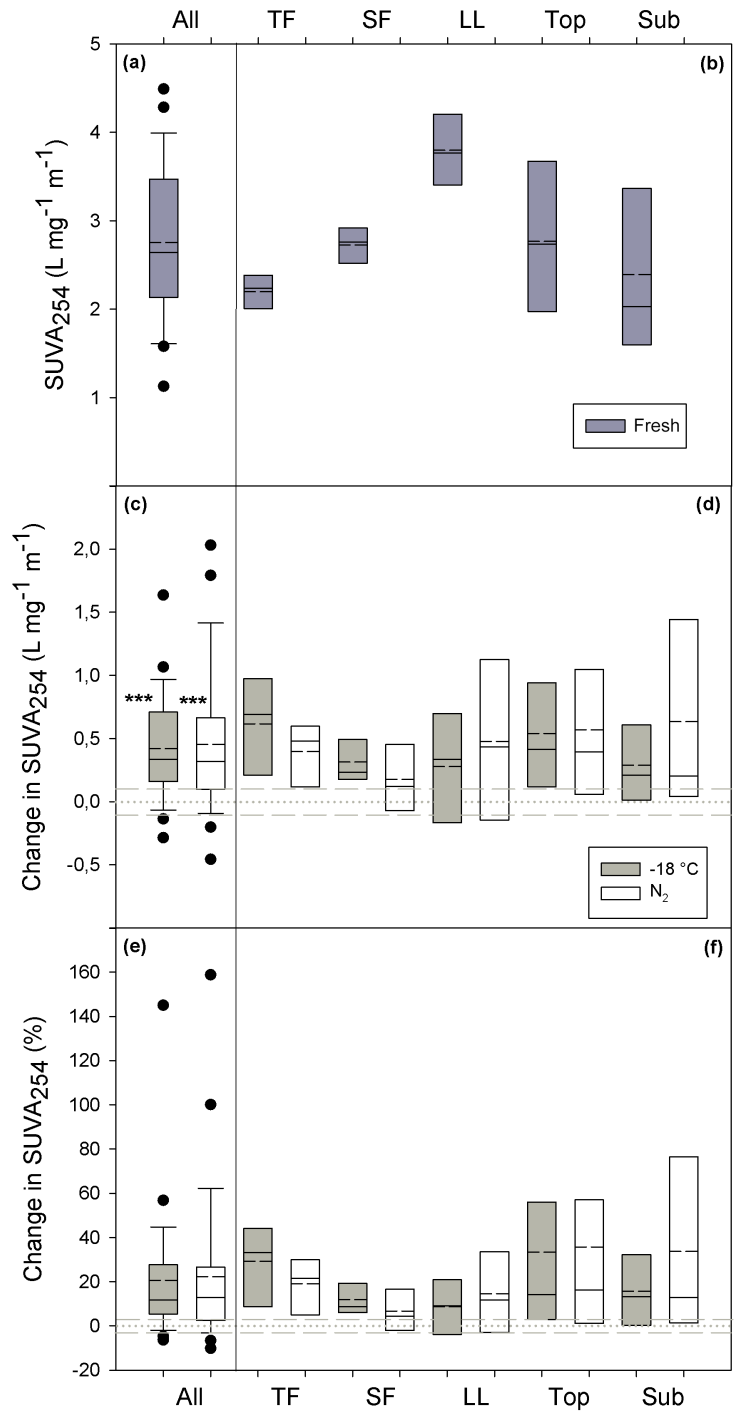

Figure 4. Absolute values (measured in fresh samples) and changes of SUVA254 after freezing $\left(-18^{\circ} \mathrm{C}\right)$ and fast-freezing with liquid nitrogen; (a, c, e) all samples $(n=27) ;(\mathbf{b}, \mathbf{d}, \mathbf{f})$ ordered by sample type (throughfall (TF) $n=6$, stemflow (SF) $n=5$, litter leachate (LL) $n=5$, top soil solution (Top) $n=6$, sub-soil solution (Sub) $n=5$ ); gray dashed line: analytical reproducibility; ${ }^{* * *}$ significant changes (linear mixed models (lme), $p<0.05$ ); boxplots: solid line: median, dashed line: mean.

cDOM changes occurred not only during the freezing process $\left(-18\right.$ or $-196^{\circ} \mathrm{C}$ in liquid nitrogen), but also in frozen state at $-18^{\circ} \mathrm{C}$ in the freezer during storage or (ii) cDOM was affected by the thawing process that was identical for both freezing treatments. The former might be supported by a re-crystallization of ice crystals in frozen state (Luyet, 1967; Meryman, 2007).

No significant changes of protein-like fluorescence $(\% \mathrm{C} 4)$ due to freezing and thawing were observed. This is in contrast to the results of Spencer et al. (2007) and Santos et

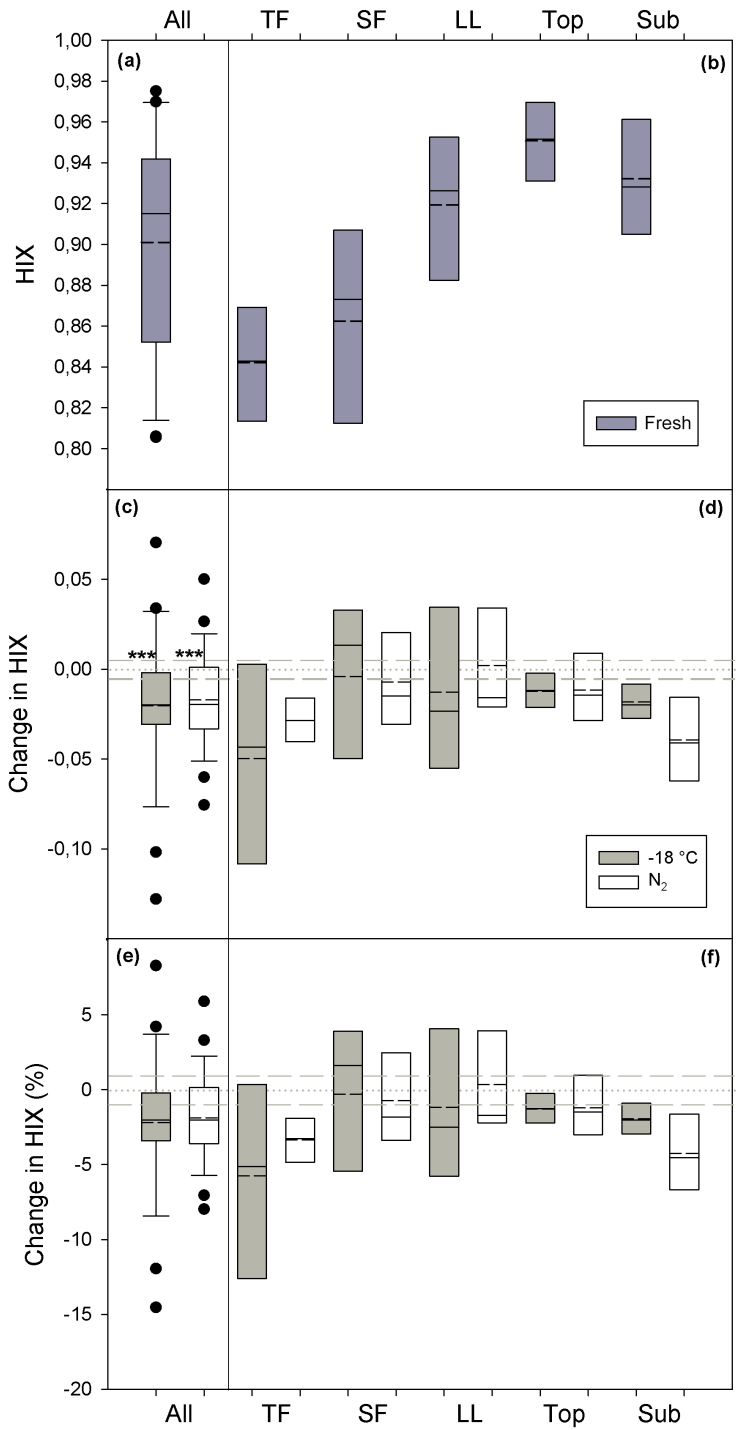

Figure 5. Absolute values (measured in fresh samples) and changes of HIX after freezing $\left(-18{ }^{\circ} \mathrm{C}\right)$ and fast-freezing with liquid nitrogen; $(\mathbf{a}, \mathbf{c}, \mathbf{e})$ all samples $(n=27) ;(\mathbf{b}, \mathbf{d}, \mathbf{f})$ ordered by sample type (throughfall (TF) $n=6$, stemflow (SF) $n=5$, litter leachate (LL) $n=5$, top soil solution (Top) $n=6$, sub-soil solution (Sub) $n=5$ ); gray dashed line: analytical reproducibility; ${ }^{* * *}$ significant changes (linear mixed models (lme), $p<0.05$ ); boxplots: solid line: median, dashed line: mean.

al. (2010), which could be related to similar fluorescence characteristics, but different chemical composition of proteinaceous fluorescence material from aquatic sources and the solutions from terrestrial ecosystems tested in this study.

In our experiment we used relative small sample volumes (fresh, $-18^{\circ} \mathrm{C}: 20 \mathrm{~mL}, \mathrm{~N}_{2}: 12 \mathrm{~mL}$ ) because we commonly keep the volume that is stored frozen as small as possible due to space limitations in deep freezers. We think that increasing the volume of samples that are subjected to freezing 
also increases the risk of artifacts, because of increasing concentration effects due to extended freezing time.

\section{Conclusions}

Freezing and thawing affected the DOC concentration, spectral absorption and fluorescence properties of water samples (throughfall, litter leachate and soil solution) from different terrestrial ecosystems (grasslands and forests). In contrast, fast-freezing with liquid nitrogen minimized the changes of bulk DOC concentrations but not the changes of spectroscopic cDOM properties. Different thawing protocols for minimizing sample storage effects on DOM should be tested in future studies. We suggest the use of fast-freezing for preservation of bulk DOC concentrations, especially for highly concentrated samples, when the increased effort and cost of using liquid nitrogen in the field is justified by advantages regarding the minimization of freezing artefacts. To preserve cDOM characteristics of samples from terrestrial sources normal freezing or fast-freezing should be avoided. Instead, filtration, cooling and measurements soon after the sampling should be the method of choice, if possible.

\section{Information about the Supplement}

The data related to statistical analysis and for generating the figures are available in the Supplement.

\section{The Supplement related to this article is available online at doi:10.5194/bg-13-4697-2016-supplement.}

Author contributions. Lisa Thieme, Martin Kaupenjohann, and Jan Siemens designed the experiment, Lisa Thieme performed the experiments. All authors analyzed the data and wrote the manuscript.

Acknowledgements. We thank the managers of the three Exploratories, Kirsten Reichel-Jung, Swen Renner, Katrin Hartwich, Sonja Gockel, Kerstin Wiesner, and Martin Gorke for their work in maintaining the plot and project infrastructure; Christiane Fischer and Simone Pfeiffer for giving support through the central office, Michael Owonibi for managing the central data base, and Markus Fischer, Eduard Linsenmair, Dominik Hessenmöller, Jens Nieschulze, Daniel Prati, Ingo Schöning, François Buscot, Ernst-Detlef Schulze, Wolfgang W. Weisser and the late Elisabeth Kalko for their role in setting up the Biodiversity Exploratories project.

The work has been (partly) funded by the DFG Priority Program 1374 "Infrastructure-Biodiversity-Exploratories" (SI 1106/4$1,2)$. D. Graeber was supported by a grant from the Danish Centre for Environment and Energy, Aarhus University.
Field work permits were issued by the responsible state environmental offices of Baden-Württemberg, Thüringen, and Brandenburg (according to $\S 72$ BbgNatSchG). We thank Sabine Dumke and Robert Jonov for sample measurement. And we thank three anonymous referees whose comments helped to improve this manuscript.

Edited by: T. Treude

Reviewed by: three anonymous referees

\section{References}

Baker, A., Elliott, S., and Lead, J. R.: Effects of filtration and $\mathrm{pH}$ perturbation on freshwater organic matter fluorescence, Chemosphere, 67, 2035-2043, 2007.

Belzile, C., Gibson, J. A. E., and Vincent, W. F.: Colored dissolved organic matter and dissolved organic carbon exclusion from lake ice: Implications for irradiance transmission and carbon cycling, Limnol. Oceanogr., 47, 1283-1293, 2002.

Bolan, N. S., Adriano, D. C., Kunhikrishnan, A., James, T., McDowell, R., and Senesi, N.: Dissolved Organic Matter: Biogeochemistry, Dynamics, and Environmental Significance in Soils, Adv. Agron., 110, 1-75, 2011.

Christ, M. and David, M. B.: Fractionation of dissolved organic carbon in soil water: Effects of extraction and storage methods, Commun. Soil Sci. Plant, 25, 3305-3319, 1994.

Conmy, R. N., Coble, P. G., Cannizzaro, J. P., and Heil, C. A.: Influence of extreme storm events on West Florida Shelf CDOM distributions, J. Geophys. Res.-Biogeo., 114, 1-17, doi:10.1029/2009JG000981, 2009.

Del Castillo, C. E. and Coble, P. G.: Seasonal variability of the colored dissolved organic matter during the 1994-95 5NE6 and 5SW6 Monsoons in the Arabian Sea, Deep-Sea Res. Pt. II, 47, 1563-1579, 2000.

Edwards, A. C. and Cresser, M. S.: Freezing and Its Effect on Chemical and Biological Properties of Soil: Advances in Soil Science, edited by: Stewart, B. A., Springer New York, New York, NY, 59-79, 1992.

Fellman, J. B., D'Amore, D. V., and Hood, E.: An evaluation of freezing as a preservation technique for analyzing dissolved organic $\mathrm{C}, \mathrm{N}$ and $\mathrm{P}$ in surface water samples, Sci. Total Enciron., 392, 305-312, 2008.

Fellman, J. B., Hood, E., and Spencer, R. G. M.: Fluorescence spectroscopy opens new windows into dissolved organic matter dynamics in freshwater ecosystems: A review, Limnol. Oceangr., 55, 2452-2462, 2010.

Fischer, M., Bossdorf, O., Gockel, S., Hänsel, F., Hemp, A., Hessenmöller, D., Korte, G., Nieschulze, J., Pfeiffer, S., Prati, D., Renner, S., Schöning, I., Schumacher, U., Wells, K., Buscot, F., Kalko, E. K. V., Linsenmair, K. E., Schulze, E.-D., and Weisser, W. W.: Implementing large-scale and long-term functional biodiversity research: The Biodiversity Exploratories, Basic Appl. Ecol., 11, 473-485, 2010.

Giesy, J. P. and Briese, L. A.: Particulate formation due to freezing humic waters, Water Resour. Res., 14, 542-544, 1978.

Graeber, D., Gelbrecht, J., Pusch, M. T., Anlanger, C., and Schiller, D. von: Agriculture has changed the amount and composition of 
dissolved organic matter in Central European headwater streams, Sci. Total Environ., 438, 435-446, 2012.

He, Z., Ohno, T., Cade-Menun, B. J., Erich, M. S., and Honeycutt, C. W.: Spectral and Chemical Characterization of Phosphates Associated with Humic Substances, Soil Sci. Soc. Am. J., 70, 1741, doi:10.2136/sssaj2006.0030, 2006.

IUSS working group WRB: World reference base for soil resources 2014: International soil classification system for naming soils and creating legends for soil maps, World Soil Resources Reports No. 106, Rome, 2014

Kalbitz, K., Geyer, W., and Geyer, S.: Spectroscopic properties of dissolved humic substances - a reflection of land use history in a fen area, Biogeochemistry, 47, 219-238, 1999.

Lakowicz, J. R.: Principles of Fluorescence Spectroscopy, 3rd Edn., Springer Science + Business Media, 2006.

Lawaetz, A. J. and Stedmon C. A.: Fluorescence Intensity Calibration Using the Raman Scatter Peak of Water, Appl. Spectrosc., 63, 936-940, 2009.

Luyet, B.: Various Modes of Recrystallization of Ice, Physics of Snow and Ice proceedings, 1, 51-70, 1967.

Meryman, H. T.: Cryopreservation of living cells: principles and practice, Transfusion, 47, 935-945, 2007.

Murphy, K. R., Ruiz, G. M., Dunsmuir, William T. M., and Waite, T. D.: Optimized Parameters for Fluorescence-Based Verification of Ballast Water Exchange by Ships, Environ. Sci. Technol., 40, 2357-2362, 2006.

Murphy, K. R., Stedmon, C. A., Waite, T. D., and Ruiz, G. M.: Distinguishing between terrestrial and autochthonous organic matter sources in marine environments using fluorescence spectroscopy, Mar. Chem., 108, 40-58, 2008.

Murphy, K. R., Butler, K. D., Spencer, R. G. M., and Stedmon, C. A., et al.: Measurement of Dissolved Organic Matter Fluorescence in Aquatic Environments: An Interlaboratory Comparison, Environ. Sci. Technol., 44, 9405-9412, 2010.

Murphy, K. R., Stedmon, C. A., Graeber, D., and Bro, R.: Fluorescence spectroscopy and multi-way techniques. PARAFAC, Anal. Methods, 5, 6557, doi:10.1039/c3ay41160e, 2013.

Ohno, T.: Fluorescence Inner-Filtering Correction for Determining the Humification Index of Dissolved Organic Matter, Environ. Sci. Technol., 36, 742-746, 2002.

Oksanen, J., Blanchet, F. G., Kindt, R., Legendre, P., Minchin, P. R., O 'Hara, R. B., Simpson, G. L., Solymos, P., Stevens, M. H. H., and Wagner, H.: vegan: Community Ecology Package, R package version 2.2-1: http://CRAN.R-project.org/package=vegan, last access: 12 November 2015.

Otero, M., Mendonça, A., Válega, M., Santos, E. B. H., Pereira, E., Esteves, V., and Duarte, A.: Fluorescence and DOC contents of estuarine pore waters from colonized and non-colonized sediments: Effects of sampling preservation, Chemosphere, 67, 211220, 2007.

Patel-Sorrentino, N., Mounier, S., and Benaim, J. Y.: Excitationemission fluorescence matrix to study $\mathrm{pH}$ influence on organic matter fluorescence in the Amazon basin rivers, Water Res., 36, 2571-2581, 2002.

Peacock, M., Freeman, C., Gauci, V., Lebron, I., and Evans, C. D.: Investigations of freezing and cold storage for the analysis of peatland dissolved organic carbon (DOC) and absorbance properties, Environm. Sci., 17, 1290-1301, 2015.
Pinheiro, J., Bates, D., DebRoy, S., Sarkar, D., and R core team: (nlme): Linear and Nonlinear Mixed Effects Models, R package version 3.1-120: http://CRAN.R-project.org/package=nlme, last access: 12 November 2015.

$\mathrm{R}$ core team: R: A language and environment for, $\mathrm{R}$ Foundation for Statistical Computing, Vienna, Austria, 2015.

Santín, C., Yamashita, Y., Otero, X. L., Álvarez, M., and Jaffé, R.: Characterizing humic substances from estuarine soils and sediments by excitation-emission matrix spectroscopy and parallel factor analysis, Biogeochemistry, 96, 131-147, 2009.

Santos, P., Otero, M., Santos, E., and Duarte, A. C.: Molecular fluorescence analysis of rainwater: Effects of sample preservation, Talanta, 82, 1616-1621, 2010.

Shutova, Y., Baker, A., Bridgeman, J., and Henderson, R. K.: Spectroscopic characterisation of dissolved organic matter changes in drinking water treatment: From 5PARAFAC6 analysis to online monitoring wavelengths, Water Res., 54, 159-169, 2014.

Spencer, R. G., Bolton, L., and Baker, A.: Freeze/thaw and pH effects on freshwater dissolved organic matter fluorescence and absorbance properties from a number of UK locations, Water Res., 41, 2941-2950, 2007.

Spencer, R. G. and Coble, P. G.: Sampling Design for Organic Matter Fluorescence Analysis, in: Aquatic Organic Matter Fluorescence, 1st Edn., edited by: Coble, P. G., Lead, J. R., Baker, A., Reynolds, D. M., and Spencer, R. G., Cambridge environmental chemistry series, Cambridge University Perss, 125-146, 2014.

Stedmon, C. A. and Markager, S.: Tracing the production and degradation of autochthonous fractions of dissolved organic matter using fluorescence analysis, Limnol. Oceangr., 50, 1415-1426, 2005.

Stedmon, C. A., Markager, S., and Bro, R.: Tracing dissolved organic matter in aquatic environments using a new approach to fluorescence spectroscopy, Mar. Chem., 82, 239-254, 2003.

Sun, S.-Q., Cai, H.-Y., Chang, S. X., and Bhatti, J. S.: Sample storage-induced changes in the quantity and quality of soil labile organic carbon, Scientific Reports, 5, 17496, doi:10.1038/srep17496, 2015.

Traversa, A., D’Orazio, V., Mezzapesa, G. N., Bonifacio, E., Farrag, K., Senesi, N., and Brunetti, G.: Chemical and spectroscopic characteristics of humic acids and dissolved organic matter along two Alfisol profiles, Chemosphere, 111, 184-194, 2014.

Weishaar, J. L., Aiken, G. R., Bergamaschi, B. A., Fram, M. S., Fujii, R., and Mopper, K.: Evaluation of Specific Ultraviolet Absorbance as an Indicator of the Chemical Composition and Reactivity of Dissolved Organic Carbon, Environ. Sci. Technol., 37, 4702-4708, 2003.

Xue, S., Wen, Y., Hui, X., Zhang, L., Zhang Z., Wang, J., and Zhang, Y..: The migration and transformation of dissolved organic matter during the freezing processes of water, J. Environ. Sci., 27 , 168-178, 2015.

Yamashita, Y., Cory, R. M., Nishioka, J., Kuma, K., Tanoue, E., and Jaffé, R.: Fluorescence characteristics of dissolved organic matter in the deep waters of the Okhotsk Sea and the northwestern North Pacific Ocean Deep-Sea Res. Pt. II, 57, 1478-1485, 2010.

Zaritzky, N.: Physical-Chemical Principles in Freezing, in: Handbook of frozen food processing and packaging, edited by: Sun, D.-W., CRC Press, 3-32, 2006. 